\title{
Prevalence of presbyopia among smoking population
}

\author{
Mohammad Khalaj', Hafez Gasemi ${ }^{*}$, Ameneh Barikani ${ }^{3}$, Morteza Ebrahimi ${ }^{4}$ and Shahram Rastak ${ }^{5}$ \\ *Correspondence: hafez1616@gmail.com

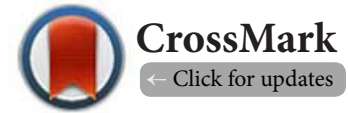 \\ ${ }^{1}$ Associate Professor, Qazvin University of Medical Sciences, Qazvin, Iran. \\ ${ }^{2}$ Faculty Member, College of Health, Qazvin University of Medical Sciences, Qazvin, Iran. \\ ${ }^{3}$ Associate Professor, Qazvin University of Medical Sciences, Qazvin, Iran. \\ ${ }^{4}$ Professor Assistance of Public Health, Department of Medical Science, Qazvin Medical \\ University, Qazvin, Iran. \\ ${ }^{5}$ Faculty Member, Qazvin University of Medical Sciences, Qazvin, Iran.
}

\begin{abstract}
Background: Presbyopia is a natural part of the aging process of the eye in which the loss of flexibility of the crystalline lens takes place over a number of years. This study aimed to determine differences in age of onset and progression of presbyopia between smoking and non smoking patients in Qazvin-Iran.

Material and methods: A comparative cross-sectional study was carried out in Boali Hospital in Qazvin-Iran between 2011 and 2012. Within the context of this survey, 304 eligible participants over 30 years age were randomly selected for interview and underwent nearvision testing. Of these, 152 participants were smokers and formed the case group and 152 non-smoking people were considered control participants. Functional presbyopia was defined as requiring at least +0.75 diopter in order to read the N8 optotype at a distance of 35 $\mathrm{cm}$ in the participant's usual visual state. Optometric and ophthalmologic examinations were performed on all participants. presbyopic correction coverage were calculated and the results were analyzed using SPSS Program with $\mathrm{P}<0.05$.

Resuts: A total of 304 participants' records were evaluated. Of those, 152 cigarette smokers were categorized as samples and 152 normal patients as control group. Eighty-five patients with ages between 39-40 year among smoking group needed to use glasses for near tasks, but nobody in normal group needed presbyopic glasses. There were significant differences in the age of onset and or progression of presbyopia were detected between smoking and normal patients $(\mathrm{p}<0.05)$.

Conclusions: Our study is the first population-based investigation of presbyopia in Iran, with the aim of determining age of onset and progression of presbyopia among smoking people related to normal population. The results of this study indicate that the onset of presbyopia among smoking group was earlier than normal group. Statistically significant difference in the age of onset and progression of presbyopia was found between smoking and non-smoking patients.
\end{abstract}

Key words: Presbyopia, smoker people, prevalence, lens flexibility, accommodation

\section{Introduction}

Presbyopia is the age-related reduced accommodation and is often associated with a progressive inability to read fine print and to write [1]. The onset of presbyopia depending to the near tasks but is gradual and the patient's accommodative amplitude becomes inadequate for his or her visual needs. There are substantial optical changes in the human lens with increasing age and during accommodation, since both the magnitude and the sign of the spherical aberration change with age and stretching [2]. Good near vision is important, even among populations who use it for tasks other than reading and writing. The human lenses exhibited a distinct viscoelastic behavior and the research evidence most strongly supports a loss of elasticity of the crystalline lens, although changes in the lens's curvature result from continual growth and loss of power of the ciliary muscles. With progressive hardening and the loss of elasticity of the lens, and its ectodermal growth it will become harder and harder for the ciliary muscle to accommodate by contraction [3-5]. In contrast to this studies, schachar and Pierscionek demonstrates that lens hardness is not related to the age-related decline in accommodative amplitude [6].

The prevalence of presbyopia in different countries is reported by various studies. It is estimated that there were 1.04 billion people globally with presbyopia in 2005, of whom 517 million had no spectacles or inadequate spectacles [7]. Of 400 people aged $40-50$ years in Zanzibar, East Africa, the overall prevalence of presbyopia was $89.2 \%$. Of those who needed correction, only $17.7 \%$ had spectacles [8]. In south India of 5587 subjects 30 years of age or older, the age-, gender-, and area-adjusted prevalence of presbyopia was 55.3\% [9].

Smoking fatally affects all the major parts of the body and can even be a major contributing risk factor for visual impairment. Many studies have explored the association between smoking and age-related eye diseases ARED. A total of $61.7 \%$ of One thousand seven hundred nine persons age 
Khalaj et al. Journal of Eye and Ophthalmology 2014,

http://www.hoajonline.com/journals/pdf/2055-2408-1-1.pdf

doi: 10.7243/2055-2408-1-1

40 years and older who resided in 3 villages of Tanzania were presbyopic. A higher prevalence of presbyopia was associated with increased age, female gender, higher educational level, and residence in town [10].

The 2004 Surgeon General's report on smoking concluded that a causal relationship between smoking and nuclear cataract exists and found evidence that was suggestive of a relationship between smoking and age-related macular degeneration (AMD) [11]. A study indicated the prevalence of presbyopia of the 800 patients who lived in rural areas, was $286(35.75 \%)$ and they began showing entered presbyopia at or before the age of 38 years [12]. The onset of presbyopia in this report may be a result of environmental conditions including high average temperature, significant much ultraviolet radiation, chronic deficiency of essential amino acids, and exposure to toxic factors, particularly hair dye. Of 332 patient records by Carnevali, presbyopia developed in the reviewed Hispanic population at mean 39.31 years of age in comparison to 40.22 years in non-Hispanics [13]. No significant differences in the age of onset or progression of presbyopia were found between black and white patients [14] This result suggests other factors may play role in previously reported variation of presbyopia in black and white patients. In the year 2000, blindness or low vision, mainly caused by age-related eye diseases (ARED, including cataract, glaucoma, age-related macular degeneration [AMD], and diabetic retinopathy $[D R])$, affected more than 3.3 million Americans aged 40 years or older; this number is predicted to increase more than $50 \%$ by 2020 [15].

Smoking harms nearly every organ of the body, causes many diseases, and worsens the general health of smokers. Tobacco annually results in approximately 443,000 deaths in the United States [16]. Many studies have explored the association between smoking and ARED. The 2004 Surgeon General's report on smoking concluded that a causal relationship exists between smoking and nuclear cataract and found evidence that was suggestive of a relationship between smoking and AMD [17]. Several observational studies have determined that smoking is a strong risk factor for the development of neovascular age-related macular degeneration, cataract, and thyroid eye diseases $[18,19]$. A few studies is conducted on Prevalence of presbyopia among Smoking population in Iran , Therefore we designed this study with the aim of determining the prevalence of differences in age at onset and progression of presbyopia between smoking and non smoking patients in Qazvin-Iran.

\section{Methods}

A comparative cross-sectional study was carried out in Boali Hospital in Qazvin-Iran between 2011 and 2012. The aim of this study was to determine the correlation between the onset of presbyopia and smoking. Within the context of this survey, 304 eligible patients at least 30 years were randomly selected for interview and underwent near-vision testing.
Eligible patients were refracted and given best distance correction [10]. A nationally representative sample of 304 people aged $30-70$ years with distance visual acuity $>6 / 18$ logMar E chart [8] was selected. Of those studied enumerated 152 were categorized as samples and 152 of participants as controls, normal group were aged between 40 and 70 years of old who coming to eye cinic and were unable to read the N8 optotype with distance correction in place. Demographic data including age, gender, and education level were obtained from all participants. There were no females among smoking group and all of 152 participants were male. Before doing ocular examination, participants answered all 10 question in the questionnaire. Testing both habitual distance visual acuity (uncorrected or with current correction) and corrected near visual acuity identifies refractive error or ocular disease and enables assessment of the patient's ability to function during near tasks. Patients underwent an ophthalmic examination that included Snellen Visual acuity, color vision, slit lamp biomicroscopy of the anterior segment as well as examination of the fundus [9]. Near vision was tested and corrected to the nearest +0.75 diopter. Near visual acuity is defined as the ability to read the N8 optotype at a distance of $35 \mathrm{~cm}$ in the participant's usual visual state (using a logMar E chart) [8]. Ocular refraction was measured using both streak retinoscope and Nidek autorefractometer. Retinoscopy was performed using trial lenses to an accuracy of $0.25 \mathrm{D}$ in horizontal and vertical meridians. Snellen visual acuity measurements were taken using a standard projected eye chart with black letters on a white background. Subjective refraction was performed on the right and then the left eye of all eligible subjects, both without [uncorrected visual acuity] and with [presenting visual acuity] spectacles. Refraction was performed using an automatic objective (Nidek) and retinoscop (Heine) and the result was used as a starting point for the subsequent subjective refraction. The data collected were analysed using Spss program with $\mathrm{Chi}^{2}$ and student $\mathrm{t}$ test with $\mathrm{P}<0.05$.

\section{Results}

Three hundred and four participants were included in our study. Of those, 152 cigarette smokers were categorized as samples and 152 normal patients as control group. Smoking people were aged between 30 and 70 years with the mean age of $42.97 \pm 5.503$ and the mean age of nonsmokers was $49.67 \pm 7.273$. Onset of presbyopia among sample group was between 30 and 70 years and it was 40 to 70 years among control group. The (Table 1) shows the mean and SD of participants ages in sample and control groups.

Among smoking group, there were $45(29.61 \%)$ factory worker, $42(27.63 \%)$ with no official job and $65(42.76 \%)$ employees . Among normal group, there were 22(14.47\%) workers, 28(18.42\%) housekeepers, $10(6.58 \%)$ with no official job and $92(60.53 \%)$ were employees.

Onset of presbyopia across various ages among smoking group was different compared to normal group. As shown 
Khalaj et al. Journal of Eye and Ophthalmology 2014,

Table 1. The mean and standard deviation of participant's age (smoking, $\mathrm{n}=152$ and non-smoking, $\mathrm{n}=152$ ).

\begin{tabular}{llll}
\hline Groups & Mean & SD & P \\
\hline Smoking & 42.97 & 5.503 & \\
Unsmoking & 49.67 & 7.273 & \\
\hline
\end{tabular}

in (Table 2), onset of presbyopia in patients aged from 30 to 35 years, was $3(1.97 \%)$ among smoking group and $1(0.66 \%)$ in normal group. Nineteen of smoking group aged 36-38 years were using glasses for near task while nobody reported using glasses in normal group. Eighty-five patients with ages between 39-40 year among smoking group needed to use glasses for near tasks, but nobody in normal group needed presbyopic glasses. Among participants with $41-45$ years of ages, $20(13.16 \%)$ of smoking patients and $115(75.66 \%)$ of normal group were presbyopia. 25(16.45\%) of smoking patients below 45 years of age and 36(23.68\%) of normal group used glasses for near tasks.

There were significant differences in the age of onset and earlier progression of presbyopia was detected between smoking and normal patients $(p=0.001)$.

The results of this study showed smoking patients catch presbyopia at earlier ages than non-smoking patients.

Onset of addiction to smoking at 10-15 years of age was $9(6 \%), 16-20$ years $50(34.2 \%), 21-30$ years $58(38.9 \%)$, up to 30 years $31(20.8 \%)$ patients (Table 3 ).

Table 2. Prevalence of presbyopia among various ages in smoking and normal groups $($ no=304).

\begin{tabular}{llllll}
\hline & \multicolumn{2}{l}{ Normal group $(\mathbf{n}=152)$} & \multicolumn{2}{l}{ Smoking group $(\mathbf{n}=152)$} & $\mathbf{P}$ \\
\hline Age & No & Percent & No & Percent & \\
$35-30$ & 1 & 0.66 & 3 & 1.97 & \\
$38-36$ & 0 & 0 & 19 & 12.5 & 0.001 \\
$40-39$ & 0 & 0 & 85 & 55.92 & \\
$45-41$ & 115 & 75.66 & 20 & 13.16 & \\
$45<$ & 36 & 23.68 & 25 & 16.45 & \\
Total & 152 & 100 & 152 & 100 & \\
\hline
\end{tabular}

Table 3. Prevalence of onset age of addiction to smoking at different ages.

\begin{tabular}{llll}
\hline Age onset of smoke & No & Percent & P \\
\hline $15-10$ & 9 & 5.92 & \\
$16-20$ & 50 & 32.9 & \\
$21-30$ & 58 & 38.16 & 0.02 \\
$>30$ & 35 & 23.03 & \\
Total & 152 & 100 & \\
\hline
\end{tabular}

There was significant correlation between onset of presbyopia and onset of addiction to cigarette $\mathrm{P} \leq 0.02$.
This study reported that, 30(19.74\%) of patients in smoking group and $11(7.24 \%)$ in normal group had positive family history of smoking. There was significant correlation between onset of presbyopia and family history of smoking $(\mathrm{P}<0.01)$.

\section{Discussion}

Tobacco smoking is directly linked to many adverse health effects, such as high blood pressure, heart disease, cancer and also eye diseases. Public awareness about the risk of eye diseases associated with smoking is very low among large parts of the population in many countries worldwide. A recent study of teenagers in the UK found that only $5 \%$ identified smoking as a cause of blindness but that fear of blindness was a strong motivating factor in quitting smoking [20].

The findings in this study evaluated differences in age of onset and progression of presbyopia between smokers and nonsmokers groups. Our study indicated that the age of onset of functional presbyopia among smokers was earlier compared to nonsmokers. Most presbyopias among smoking group about $68 \%$ were reported under ages of 40 years, whereas the most prevalence of presbyopia $75.66 \%$ of normal group were shown between 41 to 45 years of ages. According to this observation estimate, almost all patients older than 40 years have presbyopia globally [21]. This study estimated that the less/least developed countries of Asia have a prevalence of around $43 \%$, with average age of onset being about 40 years. In another review, from low- and middle-income countries, Patel and West [1] found that more than half of adults over the age of 30 have presbyopia. Duarte et al., in Brazil estimated the prevalence of presbyopia in 3,000 adults of 30 years and older at 54.7 percent [22]. In southern India, Nirmalan et al., found a prevalence of 55 percent in subjects aged 30 years and older [23].

Although some studies reported the prevalence of presbyopia over the age of 30 years but it appears that the highest incidence of presbyopia is among 40 years of age and older [10]. This finding is consistent with our study that has shown a 75 percent prevalence of presbyopia among participants in normal group. And some studies found that the prevalence of presbyopia in population above 50 years of age was $85.4 \%$ [24].

Moreover smoking may increase the risk for developing some eye diseases in particular arteriosclerosis, and is a major factor contributing to the early development of age-related macular degeneration (AMD) which may lead to blindness and some forms of cataracts that are a clouding in the lens of the eye which causes blurred vision [25-27]. Among the various risk factors of cataracts, cigarette smoking is a prominent one. It has been clinically verified that cigarette smoking and the smoking of other substances lead to a substantial increase in the oxidative stress in the lens which further accelerates the development of cataract. Stopping smoking was associated with a marked, non-linear decrease of the risk of progression to $A M D$ and reduces the risk of developing cataracts $[\mathbf{2 8 , 2 9 ]}$. Studies suggested a stronger association between smoking 
Khalaj et al. Journal of Eye and Ophthalmology 2014,

http://www.hoajonline.com/journals/pdf/2055-2408-1-1.pdf

and nuclear cataract than between smoking and cortical or posterior subcapsular cataract. Compared with never smokers, smokers of 20 or more cigarettes per day are at least twice as likely to develop nuclear cataract [30]. Smoking reduces the supply of antioxidants in our eyes, which may lead to cataracts. Increased cadmium levels in cataract lenses of smokers may also affect lens enzymes such as superoxide dismutase and glutathione peroxides, which can lead to oxidative damage [31].

A number of authors have attempted to correlate cigarette smoking with the development and deterioration of diabetic retinopathy. Smoking may accelerate the development of, or worsen diabetic retinopathy, because smoking also damages blood vessels. This issue is of relevance both for individual patients and for public health, as the proportion of smokers among patients with diabetes is no smaller than that in the general population [32]. It has been demonstrated that there are higher blood flow velocities in the ophthalmic arteries and central retinal veins of long-term smokers than of nonsmokers [33]. Tobacco smoke, even passive smoke inhaled by children, can alter the tear film of eyes, exacerbating dry eye syndrome and allergic eye conditions.

Our results demonstrated that of the 152 presbyopia in smoking group, $85(55.92 \%)$ entered presbyopia at the age of 39-40 years and 22(14.47) at or before 38 years of age, whereas onset and progression of presbyopia was reported at ages 41-45 years of normal group with a total number of $115(75 / 66)$ patients. More than $32 \%$ of the smoking groups began to smoke at the age of 16 to 20 years. The study showed that the onset and progression of presbyopia among smoking group was earlier than normal group. The precies mechanism responsible for presbyopia as a resut of smoking has not been clearly understood. There was no significant difference between two group in onset of presbyopia among patients below 45 years of age. It is important to note that this type of study has become less frequent, at least in the Asia, and is difficult to compare our study with the other population-based studies, but one study reported that of the 800 presbyopes studied, 286 (35.75\%) entered presbyopia at or before the age of 38 years. Some factors such as environmental conditions including high average temperature, high of significant ultraviolet radiation, chronic deficiency of essential amino acids, and exposure to toxic factors, particularly hair dye, may play a significant role in precipitating the early onset of presbyopia [12].

\section{Conclusions}

Smoking can cause or worsen several eye disorders, whereas Stopping smoking can reduce the risk of developing cataracts [28]. Both cataract development and age-related macular degeneration, the leading causes of severe visual impairment and blindness, are directly accelerated by smoking [34]. Oxidative stress has long been hypothesized to play a major role in the development of AMD due to the high oxidative stress environment of the fundus. Importantly, these changes indicate that oxidative damage is an important factor in the mechanism of disease development [35].

In conclusion, this study indicated a strong association between smoking and the development of presbyopia. Moreover smokers have a higher risk of the more advanced presbyopia and the risk is elevated in heavy smokers. In this study the age of onset of presbyopia as a result of smoking is earlier than non-smoking group. The earlier onset of presbyopia in smoking group in this study may be a result of smoking cigarettes. However, there is no evidence in which, the mechanism by which smoking causes presbyopia to develop earlier than normal is not fully understood, but we think the destruction of antioxidant nutrients by tobacco smoke and the changes in accommodation may cause changes in the ciliary muscles, lens, capsule of the lens but are related to age and in particular to cigarette smoking.

\section{Competing interests}

The authors declare that they have no competing interests.

Authors' contributions

\begin{tabular}{|l|c|c|c|c|c|}
\hline Authors' contributions & MK & HG & AB & ME & SR \\
\hline Research concept and design & $\checkmark$ & $\checkmark$ & $\checkmark$ & $\checkmark$ & $\checkmark$ \\
\hline Collection and/or assembly of data & $\checkmark$ & $\checkmark$ & $\checkmark$ & $\checkmark$ & -- \\
\hline Data analysis and interpretation & $\checkmark$ & $\checkmark$ & $\checkmark$ & -- & $\checkmark$ \\
\hline Writing the article & $\checkmark$ & $\checkmark$ & -- & -- & -- \\
\hline Critical revision of the article & $\checkmark$ & $\checkmark$ & $\checkmark$ & $\checkmark$ & -- \\
\hline Final approval of article & $\checkmark$ & $\checkmark$ & $\checkmark$ & -- & -- \\
\hline Statistical analysis & $\checkmark$ & $\checkmark$ & -- & -- & -- \\
\hline
\end{tabular}

\section{Acknowledgement}

The authors hereby acknowledge the sincere cooperetion and supports respected research deputy of the Qazvin University of Medical Sciences, Faculty of Health.

\section{Publication history}

Senior Editor: Tatsuya Mimura, Tokyo Women's Medical University, Japan.

Editor: Carsten H. Meyer, Pallas Clinic, Switzerland.

Received: 21-Dec-2013 Revised: 20-Jan-2014

Accepted: 08-Feb-2014 Published: 08-Mar-2014

\section{References}

1. Patel I and West SK. Presbyopia: prevalence, impact, and interventions. Community Eye Health. 2007; 20:40-1. | PubMed Abstract | PubMed FullText

2. Glasser A and Campbell MC. Presbyopia and the optical changes in the human crystalline lens with age. Vision Res. 1998; 38:209-29. | Article | PubMed

3. Borish I. Clinical Refraction. 3rd ed. Chicago, IL: Professional Press; 1970.

4. Weeber HA, Eckert G, Soergel F, Meyer CH, Pechhold W and van der Heijde RG. Dynamic mechanical properties of human lenses. Exp Eye Res. 2005; 80:425-34. | Article | PubMed

5. Ghaffariyeh AR, Shahinpoor M, Soltanpour D and Honarpisheh N. Novel theory for treatment of presbyopia: Rejuvenation of zonular fibers by capsular anterior annular peripheral shrinkage (CAPS). Irn J Med Hypotheses Ideas. 2010; 4:1-3. I Pdf

6. Schachar RA and Pierscionek BK. Lens hardness not related to the agerelated decline of accommodative amplitude. Mol Vis. 2007; 13:1010-1. 
| Pdf | PubMed Abstract | PubMed FullText

7. Holden BA, Fricke TR, Ho SM, Wong R, Schlenther G, Cronje S, Burnett A, Papas E, Naidoo KS and Frick KD. Global vision impairment due to uncorrected presbyopia. Arch Ophthalmol. 2008; 126:1731-9. | Article | PubMed

8. Laviers $\mathrm{H}$. The prevalence of presbyopia and the feasibility of community distribution of near spectacles in adults in Zanzibar, East Africa. Community Eye Health. 2007; 20:73. | PubMed Abstract | PubMed FullText

9. Nirmalan PK, Krishnaiah S, Shamanna BR, Rao GN and Thomas R. A population-based assessment of presbyopia in the state of Andhra Pradesh, south India: the Andhra Pradesh Eye Disease Study. Invest Ophthalmol Vis Sci. 2006; 47:2324-8. | Article | PubMed

10. Burke AG, Patel I, Munoz B, Kayongoya A, McHiwa W, Schwarzwalder AW and West SK. Population-based study of presbyopia in rural Tanzania. Ophthalmology. 2006; 113:723-7. | Article | PubMed

11. The health consequences of smoking: a report of the Surgeon General. Atlanta (GA): US Department of Health and Human Services, Centers for Disease Control and Prevention, National Center for Chronic Disease Prevention and Health Promotion, Office on Smoking and Health; 2004.

12. Jain IS, Ram J and Gupta A. Early onset of presbyopia. Am J Optom Physiol Opt. 1982; 59:1002-4. | Article | PubMed

13. Carnevali T and Southaphanh P. A retrospective study on presbyopia onset and progression in a Hispanic population. Optometry. 2005; 76:37-46. | Article | PubMed

14. Hunter $\mathrm{H}$, Jr. and Shipp $\mathrm{M}$. A study of racial differences in age at onset and progression of presbyopia. J Am Optom Assoc. 1997; 68:171-7. I Article I PubMed

15. Congdon N, O'Colmain B, Klaver CC, Klein R, Munoz B, Friedman DS, Kempen J, Taylor HR and Mitchell P. Causes and prevalence of visual impairment among adults in the United States. Arch Ophthalmol. 2004; 122:477-85. | Article | PubMed

16. Smoking-attributable mortality, years of potential life lost, and productivity losses--United States, 2000-2004. MMWR Morb Mortal Wkly Rep. 2008; 57:1226-8. | Article | PubMed

17. The health consequences of smoking: a report of the Surgeon General. Atlanta (GA): US Department of Health and Human Services, Centers for Disease Control and Prevention, National Center for Chronic Disease Prevention and Health Promotion, Office on Smoking and Health; 2004.

18. Risk factors for neovascular age-related macular degeneration. The Eye Disease Case-Control Study Group. Arch Ophthalmol. 1992; 110:1701-8. | Article | PubMed

19. Thornton J, Kelly SP, Harrison RA and Edwards R. Cigarette smoking and thyroid eye disease: a systematic review. Eye (Lond). 2007; 21:113545. | Article | PubMed

20. Moradi P, Thornton J, Edwards R, Harrison RA, Washington SJ and Kelly SP. Teenagers' perceptions of blindness related to smoking: a novel message to a vulnerable group. Br J Ophthalmol. 2007; 91:605-7. | Article | PubMed Abstract | PubMed FullText

21. Holden BA, Fricke TR, Ho SM, Wong R, Schlenther G, Cronje S, Burnett A, Papas E, Naidoo KS and Frick KD. Global vision impairment due to uncorrected presbyopia. Arch Ophthalmol. 2008; 126:1731-9. | Article | PubMed

22. Duarte WR, Barros AJ, Dias-da-Costa JS and Cattan JM. [Prevalence of near vision deficiency and related factors: a population-based study]. Cad Saude Publica. 2003; 19:551-9. | Article | PubMed

23. Nirmalan PK, Krishnaiah S, Shamanna BR, Rao GN and Thomas R. A population-based assessment of presbyopia in the state of Andhra Pradesh, south India: the Andhra Pradesh Eye Disease Study. Invest Ophthalmol Vis Sci. 2006; 47:2324-8. | Article | PubMed

24. Sherwin JC and Mathenge W. Presbyopia, Related Functional Impairment, and Spectacle Use in Rural Kenya. International health. 2008; 8-10.

25. Patel I, Munoz B, Burke AG, Kayongoya A, McHiwa W, Schwarzwalder AW and West SK. Impact of presbyopia on quality of life in a rural African setting. Ophthalmology. 2006; 113:728-34. | Article | PubMed

26. Thornton J, Edwards R, Mitchell P, Harrison RA, Buchan I and Kelly SP. Smoking and age-related macular degeneration: a review of association. Eye (Lond). 2005; 19:935-44. | Article | PubMed

27. Evans JR, Fletcher AE and Wormald RP. 28,000 Cases of age related macular degeneration causing visual loss in people aged 75 years and above in the United Kingdom may be attributable to smoking. $\mathrm{Br} J$ Ophthalmol. 2005; 89:550-3. | Article | PubMed Abstract | PubMed FullText

28. Lindblad BE, Hakansson N, Svensson $H$, Philipson B and Wolk A. Intensity of smoking and smoking cessation in relation to risk of cataract extraction: a prospective study of women. Am J Epidemiol. 2005; 162:73-9. | Article | PubMed

29. Emma J Berrow, Hannah E Bartlett, Frank Eperjesi and Jonathan M Gibson. Risk factors for Age-related Macular Degeneration. European Ophthalmic Review. 2011; 5:143-153.

30. Kelly SP, Thornton J, Edwards R, Sahu A and Harrison R. Smoking and cataract: review of causal association. J Cataract Refract Surg. 2005; 31:2395-404. | Article | PubMed

31. Cekic O. Effect of cigarette smoking on copper, lead, and cadmium accumulation in human lens. Br J Ophthalmol. 1998; 82:186-8. | Article | PubMed Abstract | PubMed FullText

32. Ford ES and Newman J. Smoking and diabetes mellitus. Findings from 1988 Behavioral Risk Factor Surveillance System. Diabetes Care. 1991; 14:871-4. | Article | PubMed

33. Kaiser HJ, Schoetzau A and Flammer J. Blood flow velocity in the extraocular vessels in chronic smokers. Br J Ophthalmol. 1997; 81:133-5. | Article | PubMed Abstract | PubMed FullText

34. Solberg $\mathrm{Y}$, Rosner $\mathrm{M}$ and Belkin $\mathrm{M}$. The association between cigarette smoking and ocular diseases. Surv Ophthalmol. 1998; 42:535-47. I Article | PubMed

35. Cano M, Thimmalappula R, Fujihara M, Nagai N, Sporn M, Wang AL, Neufeld AH, Biswal S and Handa JT. Cigarette smoking, oxidative stress, the anti-oxidant response through Nrf2 signaling, and Age-related Macular Degeneration. Vision Res. 2010; 50:652-64. | Article | PubMed Abstract | PubMed FullText

Citation:

Khalaj M, Gasemi H, Barikani A, Ebrahimi M and Rastak S. Prevalence of presbyopia among smoking population. J Eye Ophthalmol. 2014; 1:1. http://dx.doi.org/10.7243/2055-2408-1-1 